\title{
Analysis of the inhibition of PAI-1 by metal theaflavin complexes and their degradation products
}

\author{
JERZY JANKUN $^{1-3}$, VICTOR KONDRAY $^{1}$ and EWA SKRZYPCZAK-JANKUN ${ }^{1}$ \\ ${ }^{1}$ Urology Research Center, Department of Urology, College of Medicine, University of Toledo, Toledo, OH 43614, USA; \\ ${ }^{2}$ Protein Research Chair, Department of Biochemistry, College of Sciences, King Saud University, Riyadh 11451, \\ Saudi Arabia; ${ }^{3}$ Department of Clinical Nutrition, Medical University of Gdańsk, 80-211 Gdańsk, Poland
}

Received December 6, 2012; Accepted February 8, 2013

DOI: $10.3892 /$ ijmm.2013.1308

\begin{abstract}
The inhibition of elements of the plasminogen activator system [urokinase (uPA), tissue plasminogen activator (tPA) and plasminogen activator inhibitor-1 (PAI-1)] plays an important role in human diseases. PAI-1 is overexpressed in obesity and diabetes, and the inhibition of this protein has been postulated to alleviate the symptoms of both disorders. We found that two theaflavins (TFs) from black tea inhibit PAI-1 and we suggest that the beneficial effects of drinking tea may be associated with the suppression of PAI-1 activity by theaflavins. Epidemiological studies are controversial; some studies show the beneficial effects of drinking black tea on obesity and diabetes, while others do not. TFs, a family of compounds that can comprise up to $40 \%$ the dry weight of black tea, are responsible for the characteristic color, and they are known to chelate metals. We hypothesized that the content/variety of metals present in drinking water may be one of the reasons for such controversies in the population studies. TFs are excellent chelating compounds by trapping metals into complexes; thus, the quality of water used for tea preparation may influence changes in the formation of new products according to TF affinity for different metals, as well as their high molecular weight oxidation products. Our modeling and docking studies suggest that $\mathrm{TF} /$ metal complexes have similar affinity to PAI-1 as native TFs. However, analyses using liquid chromatographymass spectroscopy (LC-MS) revealed the presence of TF degradation products in tea brewed using water containing metal salts. These can further form high molecular weight oxidation products. Thus, metals present in tea could diminish the beneficial effects of black tea by reducing TF concentration via metal-induced degradation and precipitation.
\end{abstract}

Correspondence to: Dr Jerzy Jankun, Urology Research Center, Department of Urology, University of Toledo, Health Science Campus, MS 1091, 3000 Arlington Ave., Toledo, OH 43614, USA

E-mail: jerzy.jankun@utoledo.edu

Key words: plasminogen activator inhibitor, theaflavins, metal/ theaflavin complexes, black tea

\section{Introduction}

The inhibition of the elements of plasminogen activator system [urokinase (uPA) and/or tissue plasminogen activator (tPA), as well as plasminogen activator inhibitor-1 (PAI-1)] plays a role in a number of human diseases, including cancer, diabetes, kidney diseases, blood clotting disorders and others (1-5). PAI-1 is overexpressed in obesity and diabetes and the inhibition of this protein has been postulated to alleviate the side-effects of obesity and diabetes $(2,6)$. It has been shown that weight reduction substantially reduces plasma PAI-1 levels in obese individuals $(7,8)$. Moreover, PAI-1 inhibitors have been shown to reduce dietary fat-induced obesity in experimental animals followed by the reduction of circulating active PAI-1 levels in plasma (7,9). It is estimated that the pandemic of diabetes is caused by the rapidly growing prevalence of obesity (10). PAI-1 levels are elevated in type 2 diabetes and these levels correlate with the complications of diabetes (11). Festa et al (12) investigated the correlation between the incidence of diabetes and changes in PAI-1 levels over the course of five years. The increase in PAI-1 levels was associated with the rising glucose levels and the development of type 2 diabetes, which was confirmed in 140 out of 843 individuals. Moreover, it has been reported that PAI-1 inhibitors may be used as therapeutic agents in obesity-related diabetes which later results in kidney nephropathy $(13,14)$.

In our previous studies, we found that two theaflavins (TFs) of black tea inhibit PAI-1 and postulated that the beneficial effects of drinking tea may be associated with the inhibition of PAI-1 by TFs $(15,16)$. It has been revealed that drinking black tea, but not green tea, reduces the risk of type 2 diabetes in a clinical study conducted on a large population of 36,908 females and males of Singapore and Chinese origin (17). It was found that four or more cups of coffee per person caused a $30 \%$ reduction in risk of type 2 diabetes in comparison with nondaily consumers. Participants consuming one or more cups of black tea/day had a $14 \%$ reduction in the risk of diabetes and no reduction in diabetes risk was observed in the group that drank green tea (17). Beresniak et al (18) investigated tea consumption in 50 countries, based on 2009 sales data and analyzed World Health Organization data for the same countries on the occurence of diabetes. They reported a strong linear correlation between low rates of diabetes in countries where the consumption of black tea was high. However, these 
results were not supported by Boggs et al (19) who investigated the effects of coffee, tea and alcohol consumption on diabetes risk in 46,906 African American women over a 12-year period. Their results showed that African American women who drank moderate amounts of coffee or alcohol had a reduced risk of type 2 diabetes, but drinking tea was not associated with the decreased risk of diabetes.

TFs are a family of compounds that can comprise up to $40 \%$ the dry weight of black tea. They are responsible for the characteristic color $(20)$, and they are known to chelate metals $(21,22)$. We hypothesized that one reason for such controversies in the cohort studies may be differences in the presence and type of metals in the drinking water used for tea brewing. The type of metal could influence changes in the affinity for TF/metal formation and could stimulate the creation of new products induced by the presence of metals, or oxidation products of high molecular weight. Our modeling experiments revealed that TF/ metal complexes if formed, would have a similar affinity to PAI-1 as native TFs. However, liquid chromatography-mass spectroscopy (LC-MS) revealed the presence of TF degradation products that can form high molecular weight oxidation products rather than metal theaflavin complexes. Thus, metals present in tea or water can reduce the TF concentration by metal-induced precipitation and may thus reduce the health benefits of black tea.

\section{Materials and methods}

Molecular modeling. The structure of PAI-1, entry 3r41, was downloaded from the RCSB Protein Data Bank (23). Two dimensional (2D) TF structures were created by Accelrys Draw version 4.0 in 'SKC' format. 2D structures were converted into three dimensional (3D) and 'PDB' format files by web based programs (http://pasilla.health.unm.edu/tomcat/biocomp/ convert or http://www.molecular-networks.com/products). The docking TFs or their products to PAI-1 was performed using AutoDock Vina (24). A search box was set up with following parameters: center: $\mathrm{x}=-4.1, \mathrm{y}=10.2, \mathrm{z}=29.3$; size: $\mathrm{x}=50, \mathrm{y}=50$, $\mathrm{z}=50$ that include approximately a third of the PAI-1 molecule and the entire reactive center loop of PAI-1 with its active site. TF molecules were kept flexible by allowing rotation around single bonds. By default, AutoDock Vina analyzes eight different protein/TF complexes (different conformers) and the one with the lowest free energy is considered the most probable. Free energy can be converted to $\mathrm{K}_{\mathrm{i}}$ by the following formula (24-28):

$$
\mathrm{K}_{\mathrm{i}}=\exp \left(\Delta \mathrm{G} /\left(\mathrm{R}^{*} \mathrm{~T}\right)\right)
$$

The final analyses of structures generated by AutoDock and figure generation were performed utilizing PyMOL version $1.4(29,30)$.

Tea brewing. Black tea was brewed under controlled conditions. Specifically, a Kroger brand (Tetley) value pack of 80 teabags was purchased at a local grocery store. Tea bags were paired and weighed out (typically between 2.50-2.70 g) to possibly equalize the concentration of the tea components. The ions chosen for detection in this experiment were: calcium $(\mathrm{Ca})^{2+}$, iron $(\mathrm{Fe})^{3+}$, magnesium $(\mathrm{Mg})^{2+}$, manganese $(\mathrm{Mn})^{2+}$ and sodium $(\mathrm{Na})^{+}$. The concentrations of stock solutions were: $4 \mathrm{~g} / 1,000 \mathrm{ml}$ of metal chloride salts i.e., $0.4 \%(\mathrm{w} / \mathrm{v})$, and were further diluted to $0.04,0.004$ and $0.0004 \%(\mathrm{w} / \mathrm{v})$. Two $500-\mathrm{ml}$ volumetric flasks were filled up to $250 \mathrm{ml}$, one with distilled water for the control, and the other with the solution of the specified metal concentration, heated to $90^{\circ} \mathrm{C}$ and tea bags were immersed into the flasks. Tea was brewed for $5 \mathrm{~min}$ and stirred once every minute. Subsequently, the tea bags were removed from the brew and flasks were placed on ice to delay chemical reactions. Tea samples were centrifuged at $300 \mathrm{x}$ g for $5 \mathrm{~min}$, precipitants were dried under a vacuum, and supernatants were diluted 1:50 with distilled water for spectroscopy analysis $(250-800 \mathrm{~nm})$.

Mass spectrometry. Samples were analyzed at the Small Molecule Mass Spectrometry Facility at the Harvard FAS Center for Systems Biology, Cambridge, MA. Precipitants were solubilized in $200 \mu \mathrm{l}$ water or $200 \mu \mathrm{l}$ water/acetonitrile (50:50 v/v) before being run by LC-MS using a high accuracy Agilent ESI-TOF mass spectometer (Agilent Technologies, Santa Clara, CA) and a 45-min reverse phase gradient elution from 0 to $100 \%$ acetonitrile $(0.1 \%$ formic acid). The data were examined for ions of the target formulas: $\mathrm{C}_{8} \mathrm{H}_{10} \mathrm{~N}_{4} \mathrm{O}_{2}, \mathrm{C}_{29} \mathrm{H}_{24} \mathrm{O}_{12}$, $\mathrm{C}_{29} \mathrm{H}_{22} \mathrm{MeO}_{12}, \mathrm{C}_{29} \mathrm{H}_{20} \mathrm{Me}_{2} \mathrm{O}_{12}, \mathrm{C}_{36} \mathrm{H}_{28} \mathrm{O}_{16}, \mathrm{C}_{36} \mathrm{H}_{26} \mathrm{MeO}_{16}$, $\mathrm{C}_{36} \mathrm{H}_{24} \mathrm{Me}_{2} \mathrm{O}_{16}, \mathrm{C}_{43} \mathrm{H}_{32} \mathrm{O}_{20}, \mathrm{C}_{43} \mathrm{H}_{30} \mathrm{MeO}_{20}, \mathrm{C}_{43} \mathrm{H}_{28} \mathrm{Me}_{2} \mathrm{O}_{20}$, $\mathrm{C}_{58} \mathrm{H}_{46} \mathrm{O}_{24} \mathrm{Me}, \mathrm{C}_{72} \mathrm{H}_{54} \mathrm{O}_{32} \mathrm{Me}, \mathrm{C}_{86} \mathrm{H}_{62} \mathrm{O}_{40} \mathrm{Me}, \mathrm{C}_{43} \mathrm{H}_{28} \mathrm{Me}_{2} \mathrm{O}_{20}$, $\mathrm{C}_{29} \mathrm{H}_{24} \mathrm{O}_{13}, \mathrm{C}_{29} \mathrm{H}_{22} \mathrm{O}_{13}, \mathrm{C}_{28} \mathrm{H}_{22} \mathrm{O}_{11}, \mathrm{C}_{29} \mathrm{H}_{22} \mathrm{Me}_{2} \mathrm{O}_{12}$; where metals can be: $\mathrm{Fe}, \mathrm{Ca}, \mathrm{Mg}, \mathrm{Mn}$ and $\mathrm{Na}$.

\section{Results}

Brewing tea. Brewing tea in solutions of different salts $\left(\mathrm{Ca}^{2+}\right.$, $\mathrm{Fe}^{3+}, \mathrm{Mg}^{2+}, \mathrm{Mn}^{2+}$ and $\left.\mathrm{Na}^{+}\right)$at the highest concentrations leads to drastic changes in color and produces precipitates of some of the tea constituents. Changes in color and amount of precipitants were depended on the salt concentration. The most dramatic changes were observed in the case of Fe; other metals produced less precipitation and no precipitation was observed in the case of $\mathrm{Na}$ at all concentrations. Examples of spectrograms are shown in Fig. 1.

Molecular modeling. We have previously shown that PAI-1 is inhibited by theaflavin-3'-gallate and theaflavin-3,3'-digallate and these bind to PAI-1 in proximity of its active site $(15,16,31)$. Both TFs can react with metal cations as shown in Fig. $2(22,32)$. That includes the interaction of TFs with Me(II) and Me(III) forming complexes $(22,33,34)$. The number of possible isomers ranges from two in case 1:1 cation:TF molecule (Fig. 2, structures 1-2 and 2-2) to 81 in case 1:2 cation:TF molecules (Fig. 2, structures 1-4 and 2-4). For this reason, we performed molecular modeling for the limited number of molecules to determine whether any differences can be detected in the binding site or binding affinity to PAI-1. We analyzed total of 32 native and metal/TF molecules. Some TF structures with Mn were not converted into 3D models and these are marked as 'NC' in Table I. Examples of the binding site are shown in Fig. 3, which were binding sites for all tested metal/TF and TF molecules. We were not able to convert dehydrotheaflavins into $3 \mathrm{D}$ structures.

The theoretical binding affinity of degradation products of TFs, such as theanaphthoquinone and theabenzoquinone suggested by O'Coinceanainn et al (22) and Tanaka et al (35) was calculated as: -7.0 and $-7.5 \mathrm{kcal} / \mathrm{mol}$, respectively (Fig. 2, structures 3-2 and 3-4). Binding such large molecules as TFs 
Table I. Calculated free energies of binding for native and metal complexes of theaflavins.

\begin{tabular}{|c|c|c|c|c|c|c|c|c|}
\hline Metal & $\begin{array}{c}\mathrm{TF}\left(1^{\prime}\right) \\
\mathrm{kcal} / \mathrm{mol}\end{array}$ & $\begin{array}{l}\mathrm{TF}\left(1^{\prime}\right) \mathrm{Me} \\
\mathrm{kcal} / \mathrm{mol}\end{array}$ & $\begin{array}{c}\mathrm{TF}\left(1^{\prime}\right) \mathrm{Me}_{2} \\
\mathrm{kcal} / \mathrm{mol}\end{array}$ & $\begin{array}{c}\left(\mathrm{TF}\left(1^{\prime}\right)\right)_{2} \mathrm{Me} \\
\mathrm{kcal} / \mathrm{mol}\end{array}$ & $\begin{array}{c}\mathrm{TF}(2) \\
\mathrm{kcal} / \mathrm{mol}\end{array}$ & $\begin{array}{l}\mathrm{TF}(2) \mathrm{Me} \\
\mathrm{kcal} / \mathrm{mol}\end{array}$ & $\begin{array}{l}\mathrm{TF}(2) \mathrm{Me}_{2} \\
\mathrm{kcal} / \mathrm{mol}\end{array}$ & $\begin{array}{c}(\mathrm{TF}(2))_{2} \mathrm{Me} \\
\mathrm{kcal} / \mathrm{mol}\end{array}$ \\
\hline None & -8.2 & - & - & - & -8.9 & - & - & - \\
\hline $\mathrm{Ca}^{+2}$ & - & -8.9 & -8.9 & -8.7 & - & -9.1 & -9.3 & -9.3 \\
\hline $\mathrm{Fe}^{+2}$ & - & -9.1 & -7.9 & -7.1 & - & -8.5 & -6.9 & -8.3 \\
\hline $\mathrm{Fe}^{+3}$ & - & -6.6 & - & - & - & -6.4 & - & - \\
\hline $\mathrm{Mg}^{+2}$ & - & -8.2 & -7.9 & -7.6 & - & -8.7 & -8.9 & -6.5 \\
\hline $\mathrm{Mn}^{+2}$ & - & -7.5 & $\mathrm{NC}$ & -7.8 & - & $\mathrm{NC}$ & $\mathrm{NC}$ & -6.9 \\
\hline $\mathrm{Na}^{+}$ & - & -8.3 & -7.1 & - & - & -7.4 & -7.5 & - \\
\hline
\end{tabular}

NC, 2D structures not converted into 3D structures. TF, theaflavin; Me, metal.
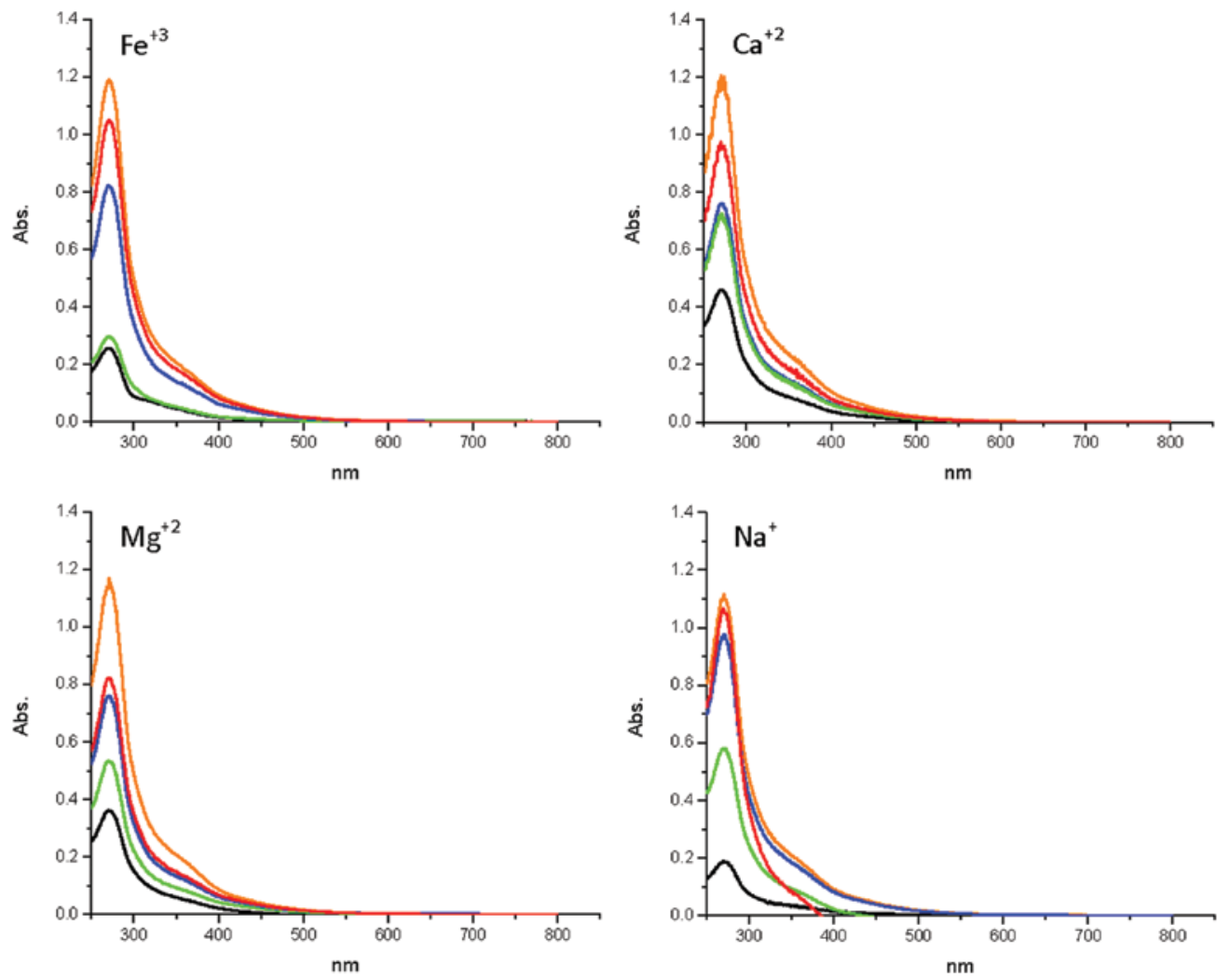

Figure 1. Examples of tea brewed in: distilled water (orange); and metal chloride salts, $0.4 \%$ (black), $0.04 \%$ (green), $0.004 \%$ (blue), or 0.0004\% (w/v) (red).

in the proximity of the PAI-1 reactive loop can interfere with its binding to uPA or tPA, inactivating PAI-1 (36). As shown in Table I, the affinity for metal/TF was very similar to the affinity for binding native TFs to PAI-1. The authors of the Vina program state that the prediction of the binding site can be modeled with high precision; however, results of affinity calculation (free energies of binding) within the range $\pm 2.5 \mathrm{kcal} / \mathrm{mol}$ are practically the same (24). As shown in Table I, some differences in the free energy of binding can be observed between native $\mathrm{TFs}$ and $\mathrm{TF} / \mathrm{Fe}^{3+}$; these cannot provide evidence of changes in affinity binding after TF reaction with metals.

Mass spectrometry. In the samples of precipitants dissolved in water we were able to identify caffeine, TFs, theaflavin-3- galate and theaflavin-3,3'-galate (Fig. 4). These compounds were also detected in all samples dissolved in water/acetonitrile. No TF ionized by protonation or its adduct ions with metals ( $\mathrm{Ca}, \mathrm{Fe}, \mathrm{K}, \mathrm{Mg}$, Mn and $\mathrm{Na}$ ) was detected. Potassium and $\mathrm{Na}$ TF derivatives are naturally found in black tea (20). In precipitants treated with water/acetonitrile we identified the following ions (Fig. 2, structures 3-2, 3-3, 3-3a and 3-4): $\left(\mathrm{m} / \mathrm{z}\right.$ 535.1142, $\mathrm{C}_{28} \mathrm{H}_{22} \mathrm{O}_{11}$-theanaphthoquinone; $\mathrm{m} / \mathrm{z}$ 579.112, $\mathrm{C}_{29} \mathrm{H}_{22} \mathrm{O}_{13}$-dehydrotheaflavin; and $\mathrm{m} / \mathrm{z}$ 717.1432, $\mathrm{C}_{36} \mathrm{H}_{28} \mathrm{O}_{16}$ theabenzoquinone) $(22,35,37)$. The assignments related to the absolute configuration ( 3 or $3^{\prime}$ ) have to be viewed with skepticism, since using mass spectroscopy, we can deduce the formula of the polyphenolic compound but not the exact orientation. 


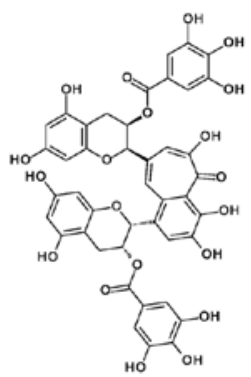

1-1

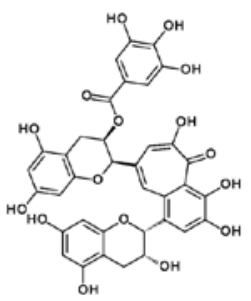

$1-2$

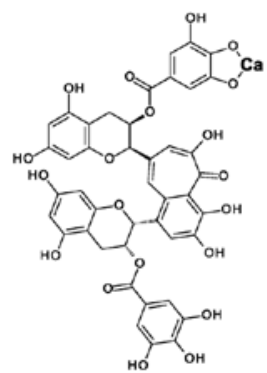

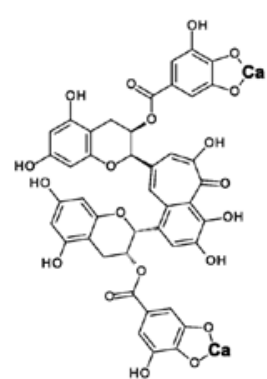

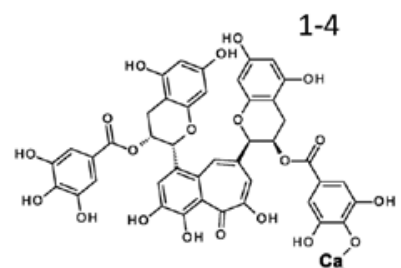

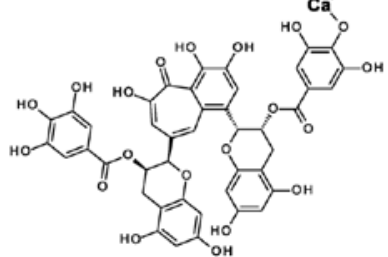

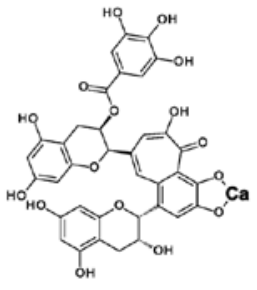

$1-3$
2-1

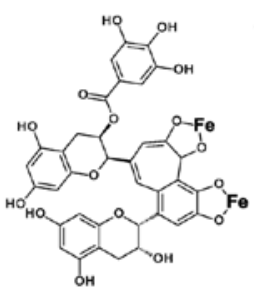

$2-2$

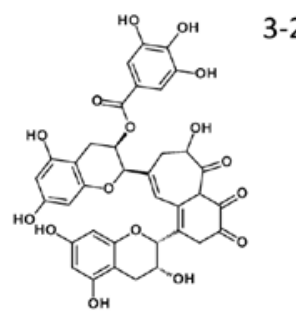

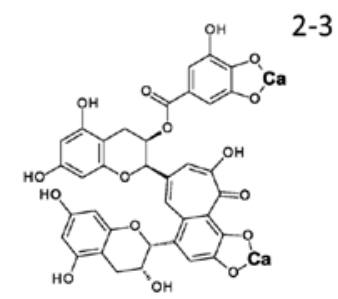

$-4$

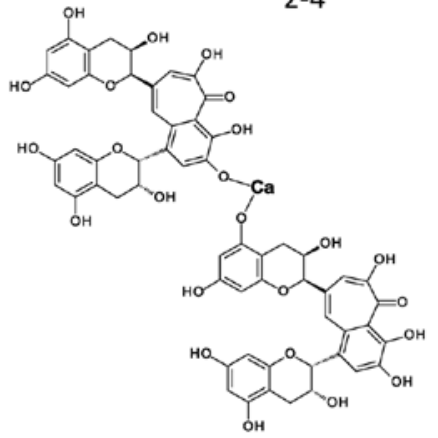

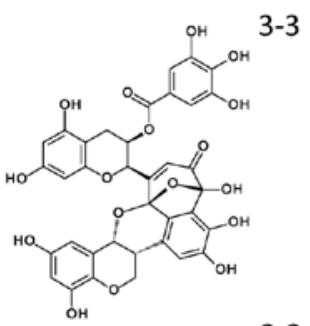

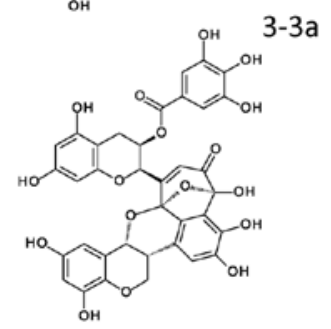

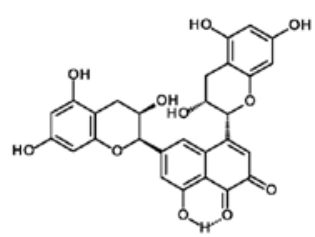

Figure 2. Structures of theaflavins, metal theaflavin complexes and degradation products.
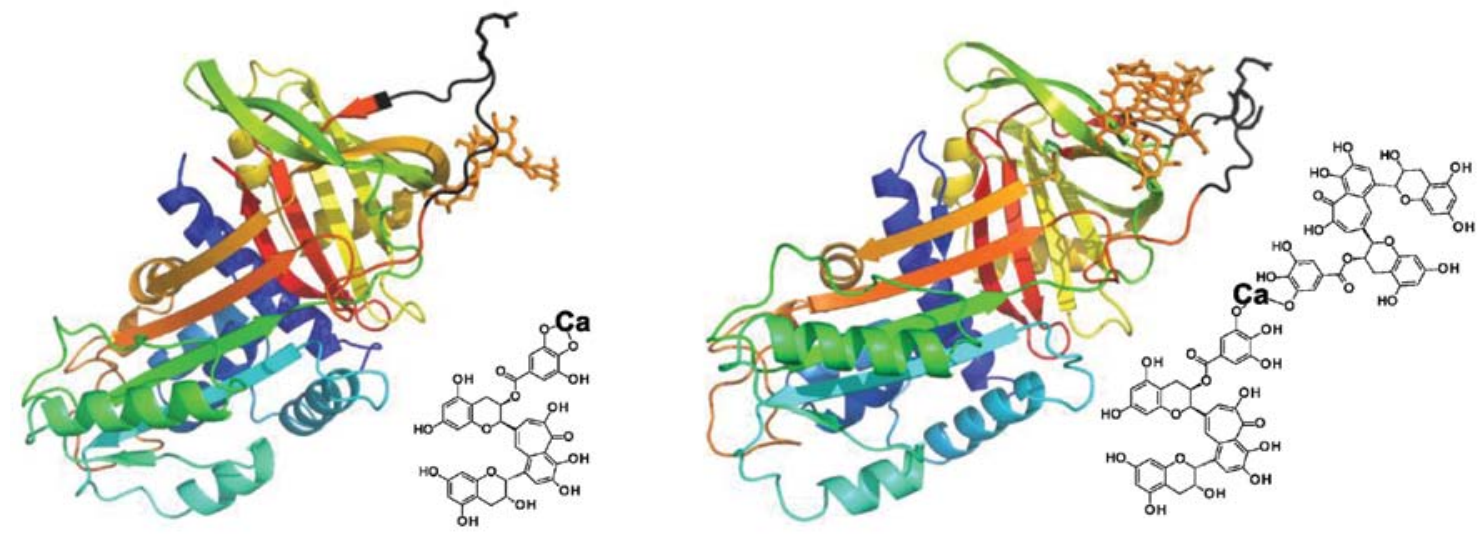

Figure 3. Ribbon model of PAI-1 and stick models of theaflavin (TF):Ca and (TF $)_{2}$ Ca complexes. Protein is colored as 'rainbow', and residues of reactive center loop 363-374 that serve as bait to draw uPA onto the top of the PAI-1 molecule are colored in black; Arg369 is shown as a stick model. 


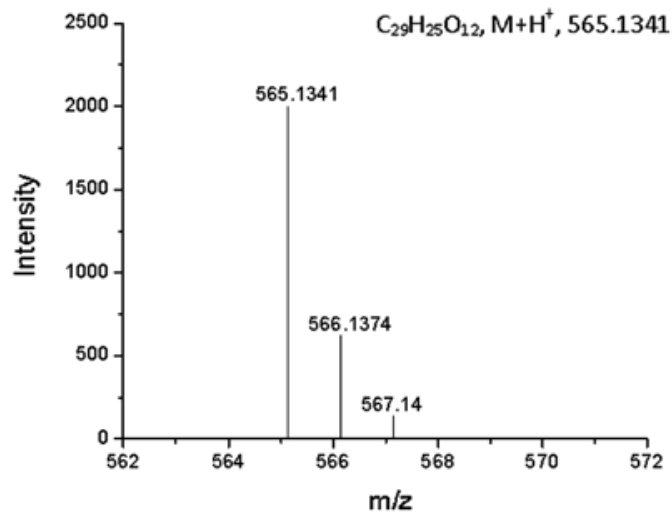

Figure 4. Mass spectrometry of theaflavin, $\mathrm{C}_{29} \mathrm{H}_{24} \mathrm{O}_{12} \mathrm{H}^{+}$.

\section{Discussion}

A number of factors can affect the health benefits of tea, such as the brand of black tea, duration of brewing and temperature, and these factors can significantly affect the content and concentration of TFs in a cup of tea (38-40). However, TFs can often have metal adduct ions associated with them instead of protonation and hydrogen (41-48) and these can influence PAI-1 inhibitory activity as well. We can envision three distinct possibilities: i) metal/TF adducts can have different affinity to PAI-1; ii) metal/TF adducts can precipitate and would not react with PAI-1; iii) metal/TF adducts degrade to smaller compounds or form non-water soluble products.

i) All investigated metals are not considered as a health hazard; however, they can alter the taste and appearance of brewed tea. Metals are present in drinking water or in tea itself. Recommendations of the maximum concentration of metals in drinking water can vary depending on the country, but in general, these levels are not higher than: $0.3 \mathrm{mg} / \mathrm{l}$ for $\mathrm{Fe}, 0.5 \mathrm{mg} / \mathrm{l}$ for $\mathrm{Mg}$, $0.3 \mathrm{mg} / \mathrm{l}$ for $\mathrm{Mn}$ and $20 \mathrm{mg} / \mathrm{l}$ for $\mathrm{Na}$. Ca levels are mostly not regulated. However, sometimes these values are much higher in drinking water, and in extreme situations can reach as high as $25 \mathrm{mg} / \mathrm{l} \mathrm{Fe}(49)$. All of these scenarios were within concentrations we investigated. Fernandez-Caceres et al (42) analyzed the metal content of 46 tea samples, including $\mathrm{Ca}, \mathrm{Fe}, \mathrm{Mg}$, $\mathrm{Mn}$ and $\mathrm{Na}$. The average content of the metals was as follows: $\mathrm{Ca}, \mathrm{Fe}, \mathrm{Mg}, \mathrm{Mn}$ and $\mathrm{Na}$ : 4,252 (range, 474-6,324), 810 (range, 74-2,036), 1978 (range, 1,489-4,272), 825 (range, 148-1,595), and 458 (range, 100-1,760) $\mathrm{mg} / \mathrm{kg}$, respectively. They found that teas from Africa and Asia differed significantly in their metal content (42). These concentrations are within the same limits that we investigated. Spectrophotometric data clearly indicate that teas brewed in water containing metals show a reaction of metal cations with the components of black tea. Since TFs can constitute up to $40 \%$ the dry weight of black tea, are responsible for the characteristic color (20), and are known to chelate metals $(21,22)$, it is highly likely that these chemicals react with metals. We hypothesized that metals are chelated as shown in Fig. 2. The molecular modeling of the binding of metal/TF and their decomposition products (Fig. 2, structures 3-2, 3-3, 3-3a and 3-4) to PAI-1 has revealed that all these chemicals bind (Fig. 3) close to Arg369 and Met370 (an active site of PAI-1) on the reactive center loop. The crystal structure of the PAI-1-uPA Michaelis complex (PDB entry 3pb1) has revealed that the
PAI-1 reactive center loop serves as bait to draw uPA onto the top of the PAI-1 molecule. The 365-374 residues of the reactive center loop interact with the uPA catalytic site, inactivating urokinase (36). Anything binding into/near this site creates an obstruction that would definitely interfere with the formation of the uPA/PAI-1 complex. Theoretical binding affinity for the aforementioned compounds was in the range of $\sim 2 \times 10^{-4}-2 \times 10^{-7}$ $(6.5-9.3 \mathrm{kcal} / \mathrm{mol})$. Since the binding affinity of native TFs was calculated as $\sim 2 \times 10^{-7}$, we cannot conclude that the chelation of metals or their decomposition will significantly affect the inhibition of PAI-1.

ii) The other possibility includes the precipitation of metal/ TF complexes that consequently will not react with PAI-1. We analyzed these by mass spectrometry. In the initial approach we analyzed precipitants treated with water. We identified caffeine, TFs, theaflavin-3-galate and theaflavin-3,3'-galate. No metal/TF molecules were found. In the following experiments, precipitants were treated with 50/50 water/acetonitrile. In these experiments we did not detect metal/TF complexes. They may not be soluble at these conditions or are not charged to be easily detected. However, in addition to compounds detected in the previous experiment we found theanaphthoquinone, dehydrotheaflavin and theabenzoquinone. The structures of these compounds can only be postulated based on the $\mathrm{m} / \mathrm{z}$ spectral data; however, supporting literature data allowed us to be confident in the assignment of these structures $(34,35)$. Furthermore, the cited authors suggest that theabenzoquinone can be further oxidized to form presumably not water soluble high molecular weight oxidation products.

iii) The coordination of aluminium, $\mathrm{Ca}, \mathrm{Fe}, \mathrm{Mg}, \mathrm{Mn}, \mathrm{Na}$ with TFs has been reported by a number of studies $(33,41-49)$. However, O'Coinceanainn et al (22) and Tanaka et al (35) suggested that the reaction between TFs involves the formation of a metal complex, followed by subsequent decomposition or formation of the non-metallic intermediates that generate high molecular weight oxidized TF products. More specifically, they suggested that metal/TFs decompose to form theabenzoquinone (Fig. 2, structure 3-2) or derivatives that form unspecified high molecular weight oxidation products. They also suggested that theabenzoquinone can form dehydrotheaflavins (Fig. 2, structures 3-3 and 3-3a) which can further degrade or form other unspecified products $(22,35,37)$.

In conclusion, we can conclude that metals present in water used for brewing tea, as well as metals naturally occuring in black tea leaves, induce a cascade of reactions during which TFs undergo significant changes, including degradation to form products of various molecular weights, or some of them can precipitate. Thus, future epidemiological studies on the health benefits of black tea should take these factors into consideration.

\section{References}

1. Al-Hamodi Z, Saif-Ali R, Ismail IS, Ahmed KA and Muniandy S: Effect of plasminogen activator inhibitor- 1 and tissue plasminogen activator polymorphisms on susceptibility to type 2 diabetes in Malaysian subjects. J Biomed Biotechnol 2012: 234937, 2012.

2. Jankun J, Al-Senaidy A and Skrzypczak-Jankun E: Can inactivators of plasminogen activator inhibitor alleviate the burden of obesity and diabetes? (Review). Int J Mol Med 29: 3-11, 2012. 
3. Jankun J, Keck RW, Skrzypczak-Jankun E and Swiercz R: Inhibitors of urokinase reduce size of prostate cancer xenografts in severe combined immunodeficient mice. Cancer Res 57: 559-563, 1997.

4. Jankun J, Merrick HW and Goldblatt PJ: Expression and localization of elements of the plasminogen activation system in benign breast disease and breast cancers. J Cell Biochem 53: 135-144, 1993.

5. Schneider DJ and Sobel BE: PAI-1 and diabetes: a journey from the bench to the bedside. Diabetes Care 35: 1961-1967, 2012.

6. De Taeye B, Smith LH and Vaughan DE: Plasminogen activator inhibitor-1: a common denominator in obesity, diabetes and cardiovascular disease. Curr Opin Pharmacol 5: 149-154, 2005.

7. Correia ML and Haynes WG: A role for plasminogen activator inhibitor-1 in obesity: from pie to PAI? Arterioscler Thromb Vasc Biol 26: 2183-2185, 2006.

8. Mavri A, Alessi MC, Bastelica D, et al: Subcutaneous abdominal, but not femoral fat expression of plasminogen activator inhibitor-1 (PAI-1) is related to plasma PAI-1 levels and insulin resistance and decreases after weight loss. Diabetologia 44: 2025-2031, 2001.

9. Crandall DL, Quinet EM, El Ayachi S, et al: Modulation of adipose tissue development by pharmacological inhibition of PAI-1. Arterioscler Thromb Vasc Biol 26: 2209-2215, 2006.

10. Ginter E and Simko V: Diabetes type 2 pandemic in 21 st century. Bratisl Lek Listy 111: 134-137, 2010.

11. Ho $\mathrm{CH}$ and Jap TS: Relationship of plasminogen activator inhibitor-1 with plasma insulin, glucose, triglyceride and cholesterol in Chinese patients with diabetes. Thromb Res 69: 271-277, 1993.

12. Festa A, Williams K, Tracy RP, Wagenknecht LE and Haffner SM: Progression of plasminogen activator inhibitor-1 and fibrinogen levels in relation to incident type 2 diabetes. Circulation 113: 1753-1759, 2006.

13. Miyata T and van Ypersele de Strihou C: Translation of basic science into clinical medicine: novel targets for diabetic nephropathy. Nephrol Dial Transplant 24: 1373-1377, 2009.

14. Nicholas SB, Aguiniga E, Ren Y, et al: Plasminogen activator inhibitor-1 deficiency retards diabetic nephropathy. Kidney Int 67: 1297-1307, 2005

15. Jankun J, Skotnicka M, Lysiak-Szydlowska W, Al-Senaidy A and Skrzypczak-Jankun E: Diverse inhibition of plasminogen activator inhibitor type 1 by theaflavins of black tea. Int J Mol Med 27: 525-529, 2011

16. Skrzypczak-Jankun E and Jankun J: Theaflavin digallate inactivates plasminogen activator inhibitor: could tea help in Alzheimer's disease and obesity? Int J Mol Med 26: 45-50, 2010

17. Odegaard AO, Pereira MA, Koh WP, Arakawa K, Lee HP and Yu MC: Coffee, tea, and incident type 2 diabetes: the Singapore Chinese Health Study. Am J Clin Nutr 88: 979-985, 2008

18. Beresniak A, Duru G, Berger G and Bremond-Gignac D Relationships between black tea consumption and key health indicators in the world: an ecological study. BMJ Open 2: 1-11, 2012.

19. Boggs DA, Rosenberg L, Ruiz-Narvaez EA and Palmer JR: Coffee, tea, and alcohol intake in relation to risk of type 2 diabetes in African American women. Am J Clin Nutr 92: 960-966, 2011

20. Menet MC, Sang S, Yang CS, Ho CT and Rosen RT: Analysis of theaflavins and thearubigins from black tea extract by MALDI-TOF mass spectrometry. J Agric Food Chem 52: 2455-2461, 2004.

21. Jobstl E, Fairclough JP, Davies AP and Williamson MP Creaming in black tea. J Agric Food Chem 53: 7997-8002, 2005

22. O'Coinceanainn M, Bonnely S, Baderschneider B and Hynes MJ: Reaction of iron(III) with theaflavin: complexation and oxidative products. J Inorg Biochem 98: 657-663, 2004.

23. Jankun J, Yang J, Zheng H, Han FQ, Al-Senaidy A and Skrzypczak-Jankun E: Remarkable extension of PAI-1 half-life surprisingly brings no changes to its structure. Int J Mol Med 29: 61-64, 2012.

24. Trott $\mathrm{O}$ and Olson AJ: AutoDock Vina: improving the speed and accuracy of docking with a new scoring function, efficient optimization, and multithreading. J Comput Chem 31: 455-461, 2010.

25. Bikadi Z,Hazai E,Zsila F and Lockwood SF: Molecular modeling of non-covalent binding of homochiral $\left(3 \mathrm{~S}, 3^{\prime} \mathrm{S}\right)$-astaxanthin to matrix metalloproteinase-13 (MMP-13). Bioorg Med Chem 14 5451-5458, 2006

26. D'Hoedt D and Bertrand D: Nicotinic acetylcholine receptors: an overview on drug discovery. Expert Opin Ther Targets 13: $395-411,2009$
27. Hetenyi C and van der Spoel D: Blind docking of drug-sized compounds to proteins with up to a thousand residues. FEBS Lett 580: 1447-1450, 2006.

28. Iorga B, Herlem D, Barre E and Guillou C: Acetylcholine nicotinic receptors: finding the putative binding site of allosteric modulators using the 'blind docking' approach. J Mol Model 12: 366-372, 2006.

29. DeLano WL: The PyMOL Molecular Graphics System, 2002. http://www.pymol.org.

30. DeLano WL: The case for open-source software in drug discovery. Drug Discov Today 10: 213-217, 2005.

31. Jankun J, Al-Senaidy A and Skrzypczak-Jankun E: Can drinking black tea fight diabetes; literature review and theoretical indication. Centr Eur J immunol 37: 167-172, 2012.

32. Yamada K, Abe T and Tanizawa Y: Black tea stain formed on the surface of teacups and pots. Part 2 - Study of the structure change caused by aging and calcium addition. Food Chem 103 $8-14,2007$.

33. O'Coinceanainn M, Astill C and Baderschneider B: Coordination of aluminium with purpurogallin and theaflavin digallate. J Inorg Biochem 96: 463-468, 2003.

34. O'Coinceanainn M and Hynes MJ: The kinetics and mechanisms of the reactions of aluminium(III) with gallic acid, gallic acid methyl ester and adrenaline. J Inorg Biochem 84: 1-12, 2001.

35. Tanaka T, Mine C and Kouno I: Structures of two new oxidation products of green tea polyphenols generated by model tea fermentation. Tetrahedron 58: 8851-8856, 2002.

36. Lin Z, Jiang L, Yuan C, et al: Structural basis for recognition of urokinase-type plasminogen activator by plasminogen activator inhibitor-1. J Biol Chem 286: 7027-7032, 2011.

37. Tanaka T, Matsuo Y and Kouno I: Chemistry of secondary polyphenols produced during processing of tea and selected foods. Int J Mol Sci 11: 14-40, 2009.

38. Kyle JA, Morrice PC, McNeill G and Duthie GG: Effects of infusion time and addition of milk on content and absorption of polyphenols from black tea. J Agric Food Chem 55: 4889-4894, 2007.

39. Lin LZ, Chen P and Harnly JM: New phenolic components and chromatographic profiles of green and fermented teas. J Agric Food Chem 56: 8130-8140, 2008

40. Yuda N, Tanaka M, Suzuki M, Asano Y, Ochi H and Iwatsuki K: Polyphenols extracted from black tea (Camellia sinensis) residue by hot-compressed water and their inhibitory effect on pancreatic lipase in vitro. J Food Sci 77: H254-H261, 2012.

41. Cabrera C, Gimenez R and Lopez MC: Determination of tea components with antioxidant activity. J Agric Food Chem 51: 4427-4435, 2003.

42. Fernandez-Caceres PL, Martin MJ, Pablos F and Gonzalez AG: Differentiation of tea (Camellia sinensis) varieties and their geographical origin according to their metal content. J Agric Food Chem 49: 4775-4779, 2001

43. Hope S, Daniel K, Gleason KL, Comber S, Nelson M and Powell JJ: Influence of tea drinking on manganese intake, manganese status and leucocyte expression of MnSOD and cytosolic aminopeptidase P. Eur J Clin Nutr 60: 1-8, 2006.

44. Matsushima F, Meshitsuka S and Nose T: Contents of aluminum and manganese in tea leaves and tea infusions. Nihon Eiseigaku Zasshi 48: 864-872, 1993 (In Japanese).

45. Polovka M, Brezova V and Stasko A: Antioxidant properties of tea investigated by EPR spectroscopy. Biophys Chem 106: 39-56, 2003.

46. Sun DM and Fang HC: Determination of trace manganese by non-organic solvents extraction catalytic spectrophotometry in $\mathrm{Mn}(\mathrm{II})-\mathrm{H}_{2} \mathrm{O}_{2}$-EBT-PEG-2000 system. Guang Pu Xue Yu Guang Pu Fen Xi 25: 1315-1317, 2005 (In Chinese).

47. Wajda $\mathrm{P}$ and Walczyk D: Nickel, cobalt, iron, manganese, zinc and chromium content of black tea and the distribution of these metals between prepared infusion and the extracted tea leaves (author's transl). Z Lebensm Unters Forsch 166: 339-343, 1978 (In German).

48. Wrobel K, Wrobel K and Urbina EM: Determination of total aluminum, chromium, copper, iron, manganese, and nickel and their fractions leached to the infusions of black tea, green tea, Hibiscus sabdariffa, and Ilex paraguariensis (mate) by ETA-AAS. Biol Trace Elem Res 78: 271-280, 2000.

49. Raji MIO, Ibrahim YKE and Ehinmidu JO: Physico-chemical characteristics and Heavy metal levels in Drinking Water sources in Sokoto metropolis in North-western Nigeria. J Appl Sci Environ Manag 14: 81-85, 2010. 